\title{
Redistribution Layer Preparation on Glass Panel for Panel Level Fan Out Package by Photosensitive Polyimide
}

\author{
Yuki Masuda, Keika Hashimoto, Yu Shoji, Yutaro Koyama, and Masao Tomikawa* \\ Electronic \& Imaging Materials Research Laboratories \\ Toray Industries, Inc., \\ 3-1-2 Sonoyama, Otsu, Shiga 520-0842, Japan \\ *masao_tomikawa@nts.toray.co.jp
}

\begin{abstract}
We successfully developed redistribution structure by using photosensitive polyimide and all wet $\mathrm{Cu}$ plating processes. To obtain the structure, patterned $\mathrm{Cu}$ was obtained by nonelectrical plating on photosensitive polyimide layer with a mask of photo-resist. Various types of surface treatments on polyimide layer were investigated to obtain good adhesion between $\mathrm{Cu}$ and polyimide. In this work, we coated the photosensitive polyimide by a slit coater and found a suitable wet surface treatment to obtain good adhesion to plated $\mathrm{Cu}$. The all wet $\mathrm{Cu}$ processes are composed of wet activation process and electro- $\mathrm{Cu}$ plating process. By combining all these processes, $40 \mu \mathrm{m}$ line and space $\mathrm{Cu}$ pattern was obtained by using a 500$600 \mathrm{~mm}$ glass panel. In addition, $2 \mu \mathrm{m}$ line and space $\mathrm{Cu}$ pattern was obtained on an $8 \mathrm{inch}$ glass wafer.
\end{abstract}

Keywords: Redistribution layer, Photosensitive polyimide, $\mathrm{Cu}$ plating

\section{Introduction}

Fan-Out Package (FO-package) is one of advanced packages due to its low profile, good electric properties, and good heat dissipation property [1]. The FO-packages are applied for application processor (AP), power management IC (PMIC), and high frequency device for smart phones [2]. Fabrication process of a current FOpackage is composed of placing a semiconductor chip on a supported wafer which was coated a mold resin, and forming re-distribution layer (RDL) on the chip and the mold resin. This process is called mold-1st process. Another process is a RDL was formed on a supported wafer, then a semiconductor chip was placed on the RDL and molded on a chip. The process is called RDL-1st.

In addition, toward a cost reduction, the FOpackage will be formed on a big glass panel [3]. In this work we report the RDL fabrication by combination of photosensitive polyimide and $\mathrm{Cu}$ plating processes on a $500 \mathrm{~mm} \times 600 \mathrm{~mm}$ glass panel with $40 \mu \mathrm{m}$ line and space. And we formed the RDL structure on an 8 inch glass wafer with $2 \mu \mathrm{m}$ line and space.

\section{Experimental}

General procedure of redistribution layer preparation was shown in Fig. 1. Photosensitive polyimide was coated on $\mathrm{Cu}$ sputtered glass substrate $(500 \mathrm{~mm} \times 600 \mathrm{~mm})$. Then $\mathrm{Ni}$ and $\mathrm{Cu}$ seed layer were plated on an activated polyimide surface. A photoresist was coated and patterned on the Ni$\mathrm{Cu}$ layer. Then, $\mathrm{Cu}$ wiring pattern was plated on the $\mathrm{Cu}$ layer as a mask of photoresist pattern. Finally, $\mathrm{Ni}-\mathrm{Cu}$ were etched. After removal from glass substrate, we obtained redistribution structure.

\subsection{Photosensitive polyimide processes}

Photosensitive Polyimide (LT-S8001, Toray) which was suitable for a slit coater was coated on a $\mathrm{Cu}$ sputtered glass substrate by the slit coater. After coating, polyimide solution was soft baked at 130 ${ }^{\circ} \mathrm{C}$ for 3 min by a hot-plate. Then the photosensitive polyimide was cured at $200{ }^{\circ} \mathrm{C}$ for $1 \mathrm{hr}$ under $\mathrm{N}_{2}$ atmosphere.

\subsection{Surface Treatment}

In order to decrease the residue on $\mathrm{Cu}$ surface and increase adhesive strength, polyimide surface was treated by plasma. In this work, we tried $\mathrm{O}_{2}$ 
ashing, $\mathrm{O}_{2}$ RIE, and Ar etching by PB-1000S (Yamato). Process conditions are summarized at Table 1.

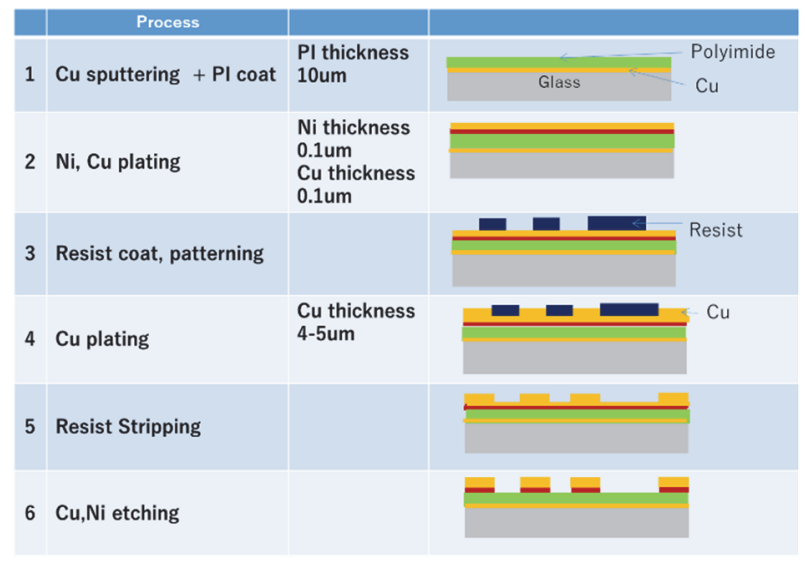

Fig. 1. Process flow of sample preparation.

Table 1. Polyimide surface treatment conditions.

\begin{tabular}{|c|c|c|c|c|c|c|}
\hline \multirow[t]{2}{*}{ No. } & \multirow[t]{2}{*}{ Gas } & \multirow[t]{2}{*}{ Mode } & \multirow{2}{*}{$\begin{array}{c}\text { RF Power } \\
\text { W }\end{array}$} & \multirow{2}{*}{$\begin{array}{c}\text { Gas Flow } \\
\mathrm{sccm} \\
\end{array}$} & \multirow{2}{*}{$\begin{array}{l}\text { time } \\
\mathrm{sec}\end{array}$} & \multirow{2}{*}{\begin{tabular}{|c|c}
$\begin{array}{c}\text { tching } \\
\text { thickness }\end{array}$ \\
um \\
\end{tabular}} \\
\hline & & & & & & \\
\hline 1 & None & & & & & 0 \\
\hline 2 & \multirow{2}{*}{02} & $P E$ & 500 & 100 & 60 & 0.2 \\
\hline 3 & & $\begin{array}{l}\mathrm{RIE} \\
\end{array}$ & 500 & 100 & 60 & 0.4 \\
\hline 4 & Ar & $\begin{array}{l}\mathrm{RIE} \\
\end{array}$ & 500 & 40 & 60 & 0.2 \\
\hline 5 & \multirow{3}{*}{02} & $\overline{P E}$ & 1000 & 100 & 60 & 0.5 \\
\hline 6 & & PE & 500 & 100 & 30 & 0.2 \\
\hline 7 & & PE & 500 & 40 & 60 & 0.4 \\
\hline
\end{tabular}

\subsection{Redistribution layer process}

Prior to $\mathrm{Cu}$ plating, we investigated the effect of wet activation condition at Okuno-chimical. Then, $\mathrm{Cu}$ plating processes were fabricated at System Integration Platform Organization Standard's (SIPOS) at Fukuoka Univ. At first, polyimide surface was treated by wet processes to adhere with $\mathrm{Ni}$ and $\mathrm{Cu}$ seed layer. Then, $\mathrm{Ni}$ and $\mathrm{Cu}$ seed layer was formed by a plating. Photoresist (P-W-1000 Tokyo Ohka Kogyo) was coated on the $\mathrm{Ni}$ and $\mathrm{Cu}$ seed layer. After patterning of photoresist, electro $\mathrm{Cu}$ plating was executed at SIPOS. Finally, photoresist was removed by acetone.

\section{Results and discussion}

\subsection{Polyimide formation}

In this work, we use LT-S8001 (Toray) for insulator. The LT-S8001 is low temperature curable photosensitive polyimide having $3-\mu \mathrm{m}$ resolution at $7-\mu \mathrm{m}$ thickness. In addition, the polyimide shows good adhesion properties to $\mathrm{Cu}$ [4]. We examined the adhesion between copper and the polyimide by a previous report [4]. In the previous work, we found that oxygen permeation in the polyimide film proceeds the $\mathrm{Cu}$ oxidation to decrease the adhesion strength. The adhesion strength did not decrease to add oxygen block layer such as spattered Ti on the polyimide layer. We found some anti-oxidant was effective to maintain adhesion strength.

In the silicon wafer, coatings of the photosensitive polyimide are usually applied using a spin coating machine, but when I use glass substrate, it may be difficult to rotate a large glass panel. So we choose a slit coater to coat a glass panel. It is necessary to apply uniform quantity to a glass interview without protruding from a slit nozzle with the varnish which came out on the substrate when it is a slit coating machine and applies it. For a slit coating, it lowers viscosity at the time of the coating, and it is necessary a solvent dries after a coating, and to raise viscosity. In addition, it is necessary to raise wetting property to raise coating uniformity. I manufactured photosensitive polyimide suitable for a slit coating machine coating in Toray and I utilized this technique and designed the photosensitivity polyimide suitable for a slit coating. I show the result that I applied, but X-Y direction achieves less than $1 \%$ of coating uniformity together (Fig. 2).

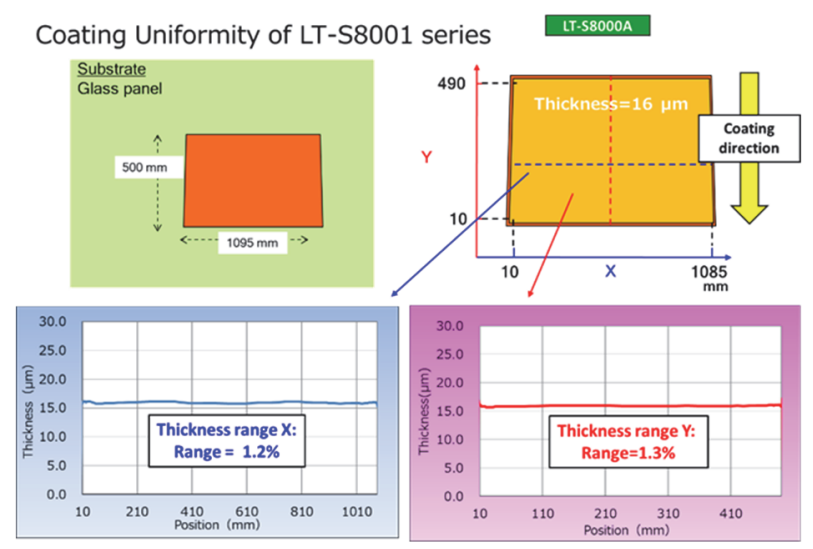

Fig. 2. Thickness uniformity by slit coating.

\subsection{Cu plating}

Prior to $\mathrm{Cu}$ plating, polyimide surface was treated by plasma. In addition, polyimide surface was treated by wet activation process. Then, thin meal seed layer, such as sputtered $\mathrm{Ti}, \mathrm{Ni}$ or $\mathrm{Cu}$ was formed. In order to make a good adhesion between polyimide and $\mathrm{Cu}$ and make a good electrical contact, we studied a plasma treatment on the polyimide surface.

The results were summarized at Tables 2 and 3 and Fig. 3. Ar treatment or $\mathrm{O}_{2}$ ashing with small $\mathrm{O}_{2}$ flow are effective to improve $\mathrm{Cu}$ adhesion. Those 
surface treatments might modify the surface roughness. On the other hand, $\mathrm{O}_{2}$ RIE did not improve the adhesion, The $\mathrm{O}_{2}$ RIE was damaged the polyimide surface deeply.

Then polyimide surface was activated by wet chemical treatment performed at Okuno chemical. Those results were also summarized at Tables 2 and 3 and Fig. 3.

Table 2. $\mathrm{Cu}$ adhesive strength for various polyimide surface treatment (without UV exposure).

\begin{tabular}{|c|c|c|c|c|c|}
\hline \multirow[b]{2}{*}{ No } & \multirow{2}{*}{$\begin{array}{l}\text { Surface } \\
\text { treatment }\end{array}$} & \multirow[b]{2}{*}{ UV } & \multicolumn{2}{|l|}{ Activation } & \multirow{2}{*}{$\begin{array}{c}\text { Cu adhesion } \\
(\mathrm{N} / \mathrm{cm})\end{array}$} \\
\hline & & & $\begin{array}{l}\text { Conc } \\
(\mathrm{ml} / \mathrm{L})\end{array}$ & $\begin{array}{c}\text { Temp } \\
\text { (C) }\end{array}$ & \\
\hline \multirow{3}{*}{1} & \multirow{3}{*}{ None } & \multirow{27}{*}{ None } & 100 & \multirow{9}{*}{30} & $<0.5$ \\
\hline & & & 250 & & $<0.5$ \\
\hline & & & 300 & & $<0.5$ \\
\hline \multirow{3}{*}{2} & \multirow{3}{*}{$\begin{array}{l}\text { O2 Ash } \\
1000 \mathrm{~W}\end{array}$} & & 100 & & $<0.5$ \\
\hline & & & 250 & & $<0.5$ \\
\hline & & & 500 & & $<0.5$ \\
\hline \multirow{5}{*}{3} & \multirow{5}{*}{ O2 RIE } & & 100 & & $<0.5$ \\
\hline & & & 250 & & $<0.5$ \\
\hline & & & 500 & & $<0.5$ \\
\hline & & & 500 & 40 & 1.1 \\
\hline & & & & 50 & 1.3 \\
\hline \multirow{5}{*}{4} & \multirow{5}{*}{ Ar plasma } & & 100 & \multirow{3}{*}{30} & $<0.5$ \\
\hline & & & 250 & & $<0.5$ \\
\hline & & & \multirow{3}{*}{500} & & $<0.5$ \\
\hline & & & & 40 & $<0.5$ \\
\hline & & & & 50 & $<0.5$ \\
\hline \multirow{3}{*}{5} & \multirow{3}{*}{$\begin{array}{l}\text { O2 Ash } \\
2000 \mathrm{~W}\end{array}$} & & 100 & 30 & $<0.5$ \\
\hline & & & 250 & \multirow{8}{*}{30} & $<0.5$ \\
\hline & & & 500 & & $<0.5$ \\
\hline \multirow{3}{*}{6} & \multirow{3}{*}{$\begin{array}{l}\text { O2 Ash } \\
30 \mathrm{sec}\end{array}$} & & 100 & & $<0.5$ \\
\hline & & & 250 & & $<0.5$ \\
\hline & & & 500 & & $<0.5$ \\
\hline \multirow{5}{*}{7} & \multirow{5}{*}{$\begin{array}{l}\text { O2 Ash } \\
40 \mathrm{sccm}\end{array}$} & & 100 & & $<0.5$ \\
\hline & & & 250 & & $<0.5$ \\
\hline & & & \multirow{3}{*}{500} & & 1.3 \\
\hline & & & & 40 & 2.9 \\
\hline & & & & 50 & 1.1 \\
\hline
\end{tabular}

First, UV process prior to activation treatment was effective to increase adhesion between $\mathrm{Cu}$ and polyimide. However, color of metal after UV treated polyimide was something dark. On the contrary, color of metal on UV untreated polyimide was shine metallic color. We expected that UV treated polyimide might be decomposed. So we choose surface treatment No.6 (low $\mathrm{O}_{2}$ flow $\mathrm{O}_{2}$ ashing) without UV for this RDL formation pre-treatment.

By changing wet activation process condition, high temperature treatment gave better $\mathrm{Cu}$ adhesion. By using the process, we obtained $40 \mu \mathrm{m}$ line $\&$ space on $500 \mathrm{~mm} \times 600 \mathrm{~mm}$ glass panel, and $2 \mu \mathrm{m}$ line $\&$ space on an 8 inch glass wafer.

Table 3. $\mathrm{Cu}$ adhesive strength for various polyimide surface treatment (with UV exposure).

\begin{tabular}{|c|c|c|c|c|c|}
\hline \multirow[b]{2}{*}{ No } & \multirow[b]{2}{*}{$\begin{array}{l}\text { Surface } \\
\text { treatment }\end{array}$} & \multicolumn{3}{|c|}{ Activation } & \multirow[b]{2}{*}{$\begin{array}{l}\text { Cu adhesion } \\
(\mathrm{N} / \mathrm{cm})\end{array}$} \\
\hline & & UV & $\begin{array}{l}\text { Conc } \\
(\mathrm{ml} / \mathrm{L})\end{array}$ & $\begin{array}{l}\text { Temp } \\
\text { (C) }\end{array}$ & \\
\hline 1 & None & \multirow{7}{*}{$1 \mathrm{~min}$} & 100 & \multirow{7}{*}{30} & 0.5 \\
\hline 2 & O2 Ash & & 100 & & 2.3 \\
\hline 3 & O2 RIE & & 100 & & 2.2 \\
\hline 4 & Ar plasma & & 100 & & 3.1 \\
\hline 5 & O2 Ash & & 100 & & 2.4 \\
\hline & O2 Ash & & 100 & & 1.1 \\
\hline 7 & O2 Ash & & 100 & & 0.5 \\
\hline
\end{tabular}

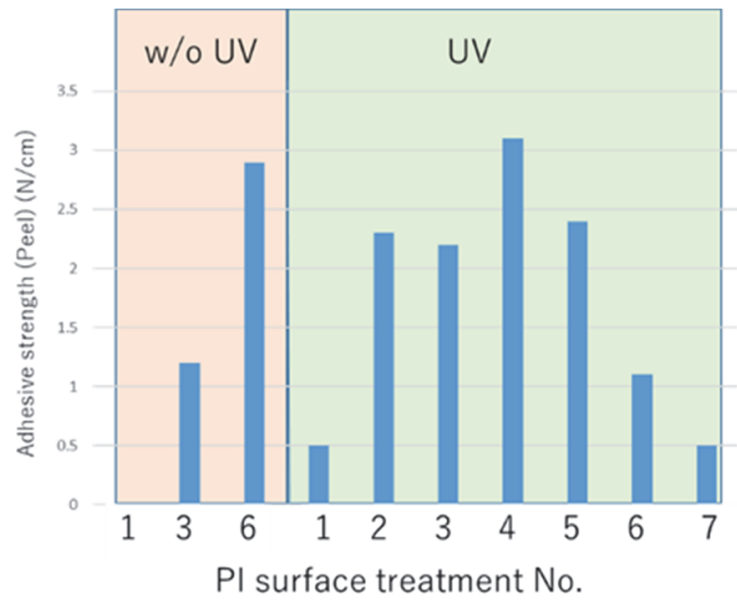

Fig. 3. Adhesive strength between $\mathrm{Cu}$ and polyimide by various polyimide surface treatment.

In addition, UV process prior to activation treatment was effective to increase adhesion between $\mathrm{Cu}$ and polyimide. However, color of metal on UV treated polyimide was some dark color. On the contrary, color of metal on UV untreated polyimide was shine metallic color. We expected that UV treated polyimide was decomposed

So we choose surface treatment No.6 (low $\mathrm{O}_{2}$ flow $\mathrm{O}_{2}$ ashing) without UV.

By changing wet activation process condition, high temperature treatment gave better $\mathrm{Cu}$ adhesion. As a result, I handled whole area using condition 2 and formed copper electric wiring. 


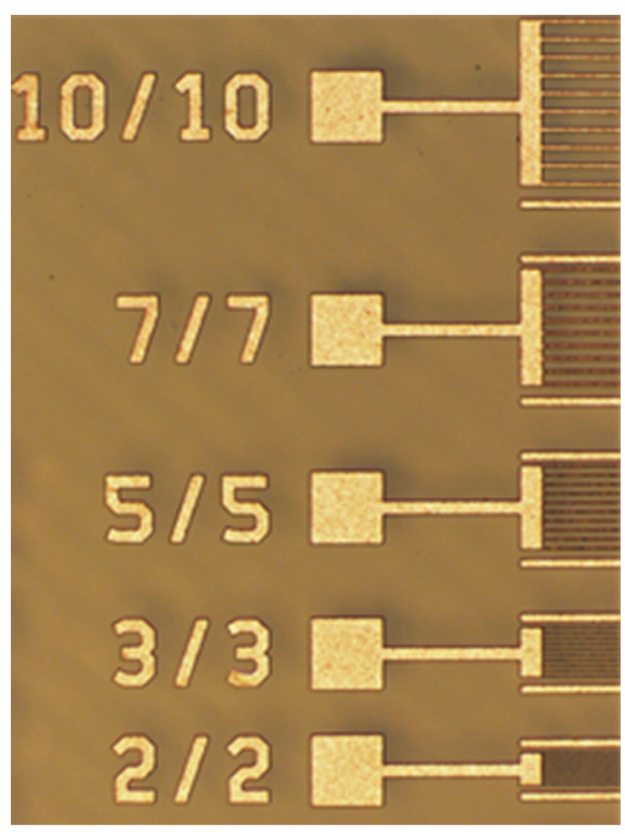

Fig. 4. Redistribution pattern on 8 inch glass wafer.

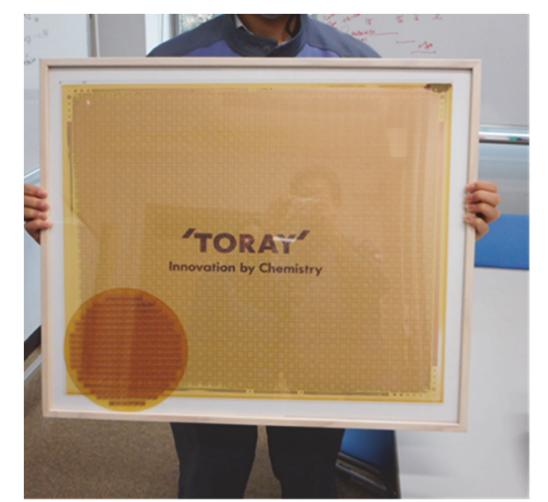

Fig. 5. Redistribution layer structures on glass panel and 8 inch glass wafer.
By using the process, we obtained $40 \mu \mathrm{m}$ line and space on $500 \mathrm{~mm} \times 600 \mathrm{~mm}$ glass panel, and $2 \mu \mathrm{m}$ line and space on an 8 inch glass wafer (Figs. 4 and $5)$.

\section{Conclusion}

Redistribution layer with combination of photosensitive polyimide and plating $\mathrm{Cu}$ was successfully obtained. $\mathrm{O}_{2}$ ashing with low flow rate of oxygen is suitable to obtain strong adhesion to metal. UV may improve the adhesion also, but metal surface was modified. By using these things, we can make $40 \mu \mathrm{m}$ line and space at $500 \mathrm{~mm} \times 600 \mathrm{~mm}$ glass substrate, and $2 \mu \mathrm{m}$ line and space at 8 inch glass wafer.

\section{Acknowledgement}

Authors are great thankfulness to Okuno Chemical and System Integration Platform Organization Standards and Research Center of Three Dimensional Semiconductors at Fukuoka Univ.

\section{References}

1. S. W. Yoon, J. A. Caparas, Y. Lin, and P. C. Marimuthu, ECTC 2012, 1250.

2. M. Brunbauer, E. Fergut, G. Beer, T. Meyeer, H. Hedler, J. Belonio, E. Nomura, K. Kikuchi, and K. Kobayashi, ECTC 2006, 56th, 5.

3. http://www.yole.fr/iso_album/illus_panellevelpackaging_playerspositioning_yole_nov_1.jpg.

4. Y. Shoji, Y. Koyama, Y. Masuda, K. Hashimoto, K. Isobe, and R. Okuda, J. Photopolym. Sci. Technol., 29 (2016) 277. 